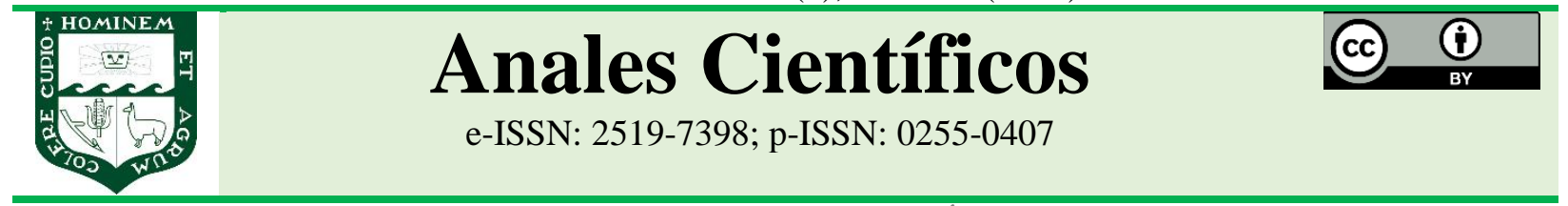

ARTÍCULO ORIGINAL - RESEARCH ARTICLE

http://dx.doi.org/10.21704/ac.v82i2.1788

\title{
REMOCIÓN DE CADMIO Y PLOMO EN UN EFLUENTE MINERO DE TICAPAMPA-RECUAY, ANCASH CON BIOMASA SECA DE Serratia marcescens M8a-2T
}

\section{Removal of cadmium and lead from a mining effluent in Ticapampa- Recuay, Ancash using Serratia marcescens M8a-2T dry biomass}

\author{
Antori Alegre Quijano ${ }^{1 *(D)}$; Susana M. Gutiérrez Moreno² \\ ${ }^{1}$ Posgrado de la Facultad de Ingeniería Geológica, Minas, Metalúrgica y Geográfica, Universidad Nacional Mayor de San Marcos, Lima 1, \\ Perú. \\ ${ }^{2}$ Laboratorio de Microbiología y Biotecnología Microbiana, Universidad Nacional Mayor de San Marcos, Lima 1, Perú. \\ * E-mail: a.alegreq@gmail.com
}

Recibido: 27/05/2020; Aceptado: 17/10/2021; Publicado: 31/12/2021

\begin{abstract}
The Ticapampa mining effluent was treated with Serratia marcescens M8a-2T dry biomass to remove polutants such as cadmium and lead. Response Surface Methodology (RSM) and Box-Behnken design matrix have been applied to optimizate the process. The influence of $\mathrm{pH}(2,3$ and 4$)$, biomass concentration $(1,2 \mathrm{and} 3 \mathrm{mg} / \mathrm{mL})$ and contact time (15, 30 and 45 minutes) were evaluated. The maximum removal percentage for cadmium was $97.11 \%$ at $\mathrm{pH} 4,2 \mathrm{mg} / \mathrm{mL}$ of biomass during 45 minutes; and for lead was $98.63 \%$ at $\mathrm{pH} 4,1 \mathrm{mg} / \mathrm{mL}$ of biomass during 30 minutes. The high levels of significance $(\mathrm{p}<0.05)$ of the regression and ANOVA models indicated $\mathrm{pH}$ as the most influencer factor. The Response Surface Methodology was a very important tool to optimize bioremediation process.
\end{abstract}

Keywords. Biosorption | heavy metals | Response Surface Methodology (RSM) | Box-Behnken design | Serratia marcescens

\section{RESUMEN}

En el presente trabajo se utilizó biomasa seca de Serratia marcescens M8a-2T con el objetivo de remover cadmio y plomo presentes en una muestra de efluente minero en concentraciones de 496,18 $\mu \mathrm{g} / \mathrm{L}$ y 513,55 $\mu \mathrm{g} / \mathrm{L}$ respectivamente. La optimización de la remoción de dichos metales se realizó usando la Metodología de Superficie de Respuesta (RSM) y el diseño experimental de Box-Behnken considerando las variables pH (2; 3 y 4), concentración de biomasa $(1 ; 2$ y $3 \mathrm{mg} / \mathrm{mL})$ y tiempo de contacto $(15 ; 30$ y 45 minutos). El porcentaje máximo de remoción de cadmio que se obtuvo fue de $97,11 \%$ a pH 4 , con $2 \mathrm{mg} / \mathrm{mL}$ de biomasa durante 45 minutos. Mientras que el porcentaje máximo de remoción de plomo fue de $98,63 \%$ a pH 4, con $1 \mathrm{mg} / \mathrm{mL}$ de biomasa durante 30 minutos de contacto. Los altos niveles de significancia $(\mathrm{p}<0.05)$ de los modelos de regresión y ANOVA obtenidos indican al pH como la variable de mayor influencia. La Metodología de Superficie de Respuesta demostró ser de mucha utilidad para optimizar procesos de biorremediación. 
Palabras clave: Bioadsorción | metales pesados | Metodología de Superficie de Respuesta (RSM) | diseño de BoxBehnken I Serratia marcescens

Forma de citar el artículo (Formato APA):

Alegre, A., \& Gutiérrez, S. (2021). Remoción de cadmio y plomo en un efluente minero de Ticapampa-Recuay, Ancash con biomasa seca de Serratia marcescens M8a-2T. Anales Científicos. 81(2), 336-345. http://dx.doi.org/10.21704/ac.v82i2.1788

Autor de correspondencia (*): Antori Alegre Quijano. Email: a.alegreq@gmail.com

(C) Los autores. Publicado por la Universidad Nacional Agraria La Molina.

This is an open access article under the CC BY

\section{INTRODUCCIÓN}

La minería es una de las principales actividades extractivas realizadas por el ser humano, pero también una de las más importantes causas de contaminación ambiental al provocar un impacto negativo en la calidad del aire, del suelo, subsuelo y del agua; además de alterar el paisaje, destruir o perturbar hábitats naturales y otros efectos que muchas veces son el motivo de conflictos sociales (Vilera-Pincay et al. 2020).

La presencia de elevadas concentraciones de metales pesados en cuerpos de agua, como consecuencia de la actividad minera, es un grave problema que requiere atención debido a que muchos de estos metales tienen efectos tóxicos. El mercurio $(\mathrm{Hg})$, arsénico (As), cromo $(\mathrm{Cr})$, plomo $(\mathrm{Pb})$, cadmio $(\mathrm{Cd})$, níquel $(\mathrm{Ni})$ y zinc $(\mathrm{Zn})$, son los más peligrosos para la mayoría de organismos acuáticos y terrestres, cuya exposición por encima de una concentración umbral puede ser extremadamente tóxica (Castañe et al. 2003). A través de los años, la extracción, procesamiento y exportación de minerales se ha establecido como una de las principales actividades económicas del Perú gracias a la gran variedad de depósitos metálicos que existe en su territorio, como consecuencia, se ha generado la acumulación de una gran cantidad de pasivos ambientales que ponen en riesgo la integridad de los ecosistemas y la salud pública (Glave \& Kuramoto 2002, CIPER 2011).

De acuerdo al último inventario de pasivos ambientales mineros (PAM), el Perú registra en su territorio 7956 PAM hasta el año 2020; donde Áncash $(15,5 \%)$, Cajamarca $(14,5 \%)$ y Puno $(11,6 \%)$ son las regiones con mayor número de pasivos. Al mismo tiempo, Cajamarca (30,7\%), Áncash $(17,5 \%)$ y Lima $(11,6 \%)$ son las regiones con mayores PAM de niveles de riesgo alto y muy alto del total registrado (921 PAM) (Castillo et al. 2021).

Por esta razón, es necesario el mejoramiento del proceso de cierre de minas, con la aplicación de métodos de remoción de metales pesados para reducir el impacto negativo sobre los ecosistemas. Los métodos fisicoquímicos más usados para remover metales pesados en aguas residuales son la filtración por membrana, el intercambio iónico, la adsorción con carbón activado, la precipitación química y la coagulación-floculación; todas ellas, aunque con altas eficiencias, presentan desventajas como elevados costos de mantenimiento y la generación de grandes cantidades de lodos que contienen metales (Rubio et al. 2015).

La biosorción (o bioadsorción) es un método alternativo que consiste en la captación de iones metálicos por medio de biomasa viva o muerta, especialmente bacterias y hongos que son aislados de ecosistemas contaminados y que, a través de mecanismos físicos y químicos, como la adsorción y el intercambio iónico son capaces de retener los metales pesados (Sandoval 2006). No es necesario agregar nutrientes al sistema (el microorganismo no requiere un metabolismo activo) y finalmente, la biomasa se extrae fácilmente del agua tratada, reduciendo los costos del proceso y evitando la formación de lodos (Cañizares 2000; Rajendran et al. 2003). Sin embargo, se trata de un método complejo que depende de diversos factores que van a influir directamente en el desarrollo y resultado final; por lo que se deben aumentar los esfuerzos para el estudio de la bioadsorción y la optimización de los parámetros que influyen en el proceso tanto a nivel de laboratorio, de escalamiento en plantas piloto y aplicaciones directas in situ (Sandoval 2006; Gutiérrez 2015).

La metodología de superficie de respuesta (RSM) es un conjunto de técnicas matemáticas y estadísticas que 
fue desarrollado por Box y Wilson en 1951 y describen la relación entre diversas variables independientes y una o más respuestas; este método se basa en el ajuste de modelos a los resultados experimentales generados a partir del diseño experimental y la verificación del modelo obtenido mediante técnicas estadísticas (Witek-Krowiak 2014).

El diseño experimental tiene una influencia importante en el costo y la precisión de calcular la superficie de respuesta, por lo que es una herramienta fundamental en el campo de la ingeniería y la biotecnología para mejorar la eficiencia de procesos (Bezerra et al. 2008), tal como lo muestran las investigaciones realizadas por Yuan et al (2019) quienes aplicaron RSM para la adsorción de cadmio por Shewanella putrefaciens y lograron optimizar el proceso con un porcentaje máximo de remoción de cadmio de 86,54\% a pH 5.0, 4 días de contacto y $20 \mathrm{mg} / \mathrm{L}$ de concentración inicial de cadmio; Choińska et al (2018) utilizaron RSM para optimizar la biosorción de Cadmio y Plomo con cepas de Pseudomonas azotoformans considerando tres factores: $\mathrm{pH}$, concentración inicial de metal y concentración del biosorbente. RSM también fue utilizada para evaluar el efecto de las variables $\mathrm{pH}$, concentración inicial de iones y velocidad de agitación sobre la efectividad de cepas de Pseudomonas para la biosorción de Arsénico (Banerjee et al 2016).

En la presente investigación se ha utilizado RSM para optimizar la remoción de cadmio y plomo de una muestra de efluente minero empleando biomasa seca de Serratia marcescens M8a-2T. Esta cepa fue aislada de un ambiente minero y a nivel de laboratorio demostró características que la hacen una buena candidata para ser usada en procesos de remoción de metales pesados mediante el mecanismo de bioadsorción; posee resistencia a estos metales, alta producción de biomasa, 98,3\% de capacidad máxima de retención en 15 minutos y es genéticamente estable (Gutiérrez 2015).

\section{MATERIALES Y MÉTODOS}

\section{Toma de muestras y análisis del efluente minero}

Para este estudio se tomaron muestras de efluente minero, a partir de un drenaje de bocamina abierto perteneciente a la etapa de explotación minera de la Compañía Minera Alianza S. A., ubicada en el distrito de Ticapampa, provincia de Recuay y departamento de Ancash (Figura 1). La muestra fue transportada hasta el laboratorio de Microbiología y Biotecnología Microbiana de la Facultad de Ciencias Biológicas Universidad Mayor de San Marcos (Lima, Perú), para determinar la concentración inicial de cadmio y plomo presentes en la muestra y realizar los ensayos de bioadsorción.

\section{Preparación de la biomasa seca}

La cepa Serratia marcescens M8a-2T usada en el presente estudio, pertenece a la colección del laboratorio de Microbiología y Biotecnología Microbiana de la Facultad de Ciencias Biológicas Universidad Mayor de San Marcos (Lima, Perú).

Para la obtención de la biomasa seca, se cultivó en caldo nutricio durante 12 a 14 horas hasta alcanzar la fase estacionaria y se centrifugó a $1000 \mathrm{~g}$ durante 30 minutos. Se descartó el sobrenadante y el precipitado se lavó 2 veces con agua destilada para quitar iones u otros residuos del medio; el precipitado final, se depositó en un crisol previamente pesado y se puso a secar a $80^{\circ} \mathrm{C}$ durante 3 a 5 horas hasta obtener un peso constante. La biomasa seca fue desprendida de los crisoles con una espátula, molida en un mortero, tamizada a través de poros de 50 micras y guardadas herméticamente en una campana de vacío (Gutiérrez 2015).

\section{Optimización de las condiciones físico-químicas para la bioadsorción}

Para el diseño experimental se utilizó el software Design-Expert (Stat Ease, versión 11.0). Se tomaron tres variables independientes (parámetros): $\mathrm{pH}$ (2, 3 y 4), concentración de biomasa (1, 2 y $3 \mathrm{mg} / \mathrm{mL})$, tiempo de contacto (15, 30 y 45 minutos); se definieron las variables dependientes (respuestas): porcentaje de remoción de cadmio y porcentaje de remoción de plomo y se seleccionó el rango de cada parámetro (mínimo y máximo) como se observa en la Tabla 1. 


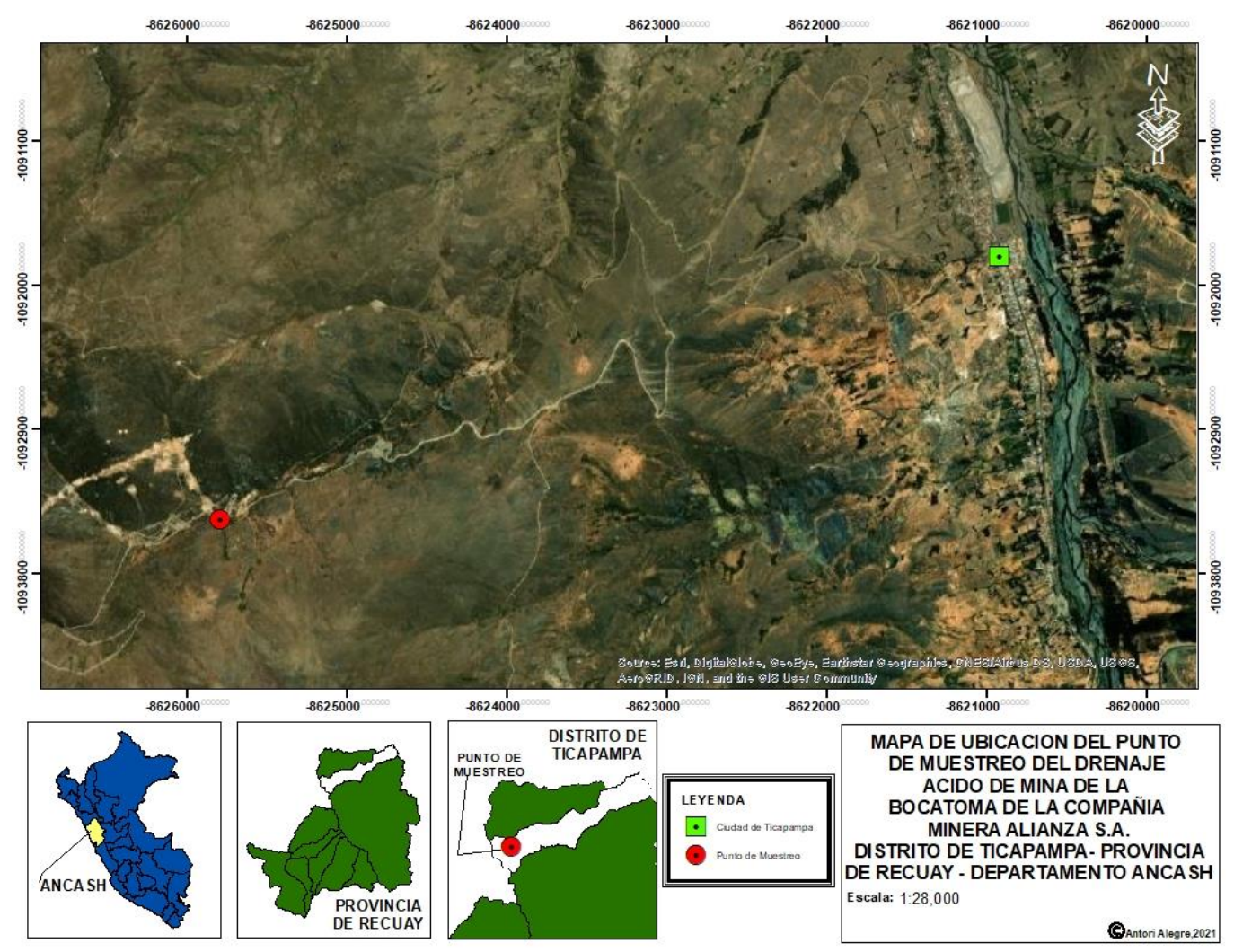

Figura 1. Ubicación del drenaje de bocamina abierto de la etapa de explotación de la Compañía Minera Alianza S.

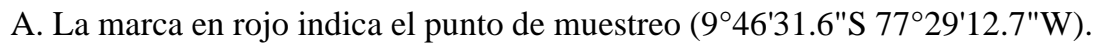

El modelo Box-Behnken produjo 17 experimentos para el diseño experimental, incluidas 5 repeticiones de los puntos centrales para el cálculo del error experimental como se observa en la Tabla 2. Todos los experimentos de bioadsorción se llevaron a cabo por triplicado en matraces estériles de 25 mililitros de capacidad con 10 mililitros de efluente minero en agitación constante a $150 \mathrm{rpm}$. Se ajustó el pH de cada matraz y se añadió a cada uno la cantidad de biomasa seca de $S$. marcescens M8a-2T según el diseño experimental; no se realizó control sin biomasa, el efluente se mantuvo en agitación constante y fue homogenizado previo a cada paso del experimento para evitar la precipitación de los metales. Finalizado el tiempo de contacto para cada experimento, el contenido de los matraces se pasó a través de filtros de jeringa provistos con membranas con porosidad de 0,45 micras, se colocó en tubos de centrífuga estériles y se midió la concentración final de cadmio y plomo de cada uno de los experimentos por Espectrometría de Masas con Plasma Acoplado Inductivamente (ICPMS), en un ICP-Masas modelo 7700X (Agilent Technologies). El porcentaje de remoción se halló por medio de la fórmula:

$\% R=\frac{(C o-C f)}{C o} \times 100$

Donde:

$\% R \quad$ : Porcentaje de remoción.

Co : Concentración inicial del soluto en $\mu \mathrm{g} / \mathrm{L}$.

Cf : Concentración final del soluto en $\mu \mathrm{g} / \mathrm{L}$. 
Tabla 1. Valores de las variables recodificadas para la optimización.

\begin{tabular}{cccccc}
\hline Parámetros & Código & Unidades & \multicolumn{2}{c}{ Rango y niveles (codificado) } \\
\cline { 4 - 6 } & & & $\mathbf{- 1}$ & $\mathbf{0}$ & $\mathbf{+ 1}$ \\
\hline pH & $\mathrm{A}$ & & 2 & 3 & 4 \\
Concentración de biomasa & $\mathrm{B}$ & $\mathrm{mg} / \mathrm{mL}$ & 1 & 2 & 3 \\
Tiempo de contacto & $\mathrm{C}$ & Minuto & 15 & 30 & 45 \\
\hline
\end{tabular}

Tabla 2. Diseño experimental de Box-Behnken para la optimización de la bioadsorción de cadmio y plomo: Parámetros y sus niveles.

\begin{tabular}{ccccccccccccccccccc}
\hline Experimento & & $\mathbf{1}$ & $\mathbf{2}$ & $\mathbf{3}$ & $\mathbf{4}$ & $\mathbf{5}$ & $\mathbf{6}$ & $\mathbf{7}$ & $\mathbf{8}$ & $\mathbf{9}$ & $\mathbf{1 0}$ & $\mathbf{1 1}$ & $\mathbf{1 2}$ & $\mathbf{1 3}$ & $\mathbf{1 4}$ & $\mathbf{1 5}$ & $\mathbf{1 6}$ & $\mathbf{1 7}$ \\
\hline $\mathbf{p H}$ & $\mathbf{X}_{\mathbf{1}}$ & 4 & 4 & 2 & 4 & 2 & 3 & 3 & 3 & 3 & 3 & 2 & 2 & 3 & 3 & 3 & 4 & 3 \\
$\begin{array}{c}\text { Concentración de } \\
\text { biomasa (mg/mL) }\end{array}$ & $\mathbf{X}_{\mathbf{2}}$ & 2 & 3 & 2 & 1 & 3 & 3 & 2 & 2 & 2 & 2 & 1 & 2 & 1 & 1 & 3 & 2 & 2 \\
$\begin{array}{c}\text { Tiempo de } \\
\text { contacto (min) }\end{array}$ & $\mathbf{X}$ & 15 & 30 & 45 & 30 & 30 & 45 & 30 & 30 & 30 & 30 & 30 & 15 & 45 & 15 & 15 & 45 & 30 \\
\hline
\end{tabular}

\section{RESULTADOS Y DISCUSIÓN}

La concentración inicial ( $C o$ ) de cadmio fue de 496,18 $\mu \mathrm{g} / \mathrm{L}(0,49618 \mathrm{mg} / \mathrm{L})$ y la concentración inicial (Co) de plomo $513,55 \mu \mathrm{g} / \mathrm{L} \quad(0,51355 \quad \mathrm{mg} / \mathrm{L})$. Estas concentraciones se encuentran por encima de los Límites Máximos Permisibles (LMP) para la descarga de efluentes líquidos de actividades minerometalúrgicas establecidos por el Estado Peruano en el Decreto Supremo $\mathrm{N}^{\circ}$ 010-2010-MINAM, el cual indica que la concentración de cadmio total no debe exceder los $0,05 \mathrm{mg} / \mathrm{L}$ y la concentración de plomo total no debe exceder los $0,2 \mathrm{mg} / \mathrm{L}$ en cualquier momento. Estos resultados indican un alto grado de contaminación del efluente minero.

\section{Modelo matemático: validación y análisis estadístico}

El cálculo de los coeficientes de la ecuación de regresión sugiere el ajuste de datos a una ecuación polinómica de segundo grado (cuadrática) para la remoción de cadmio y plomo:

$$
\begin{aligned}
& Y_{1}=+93,55+2,64 A-0,2900 B+0,9238 C- \\
& 0,0525 A B+0,0900 A C+0,9425 B C-0,2635 A^{2}+ \\
& 0,9790 B^{2}-0,7785 C^{2}
\end{aligned}
$$

$Y_{2}=+96,98+1,09 A-1,79 B-3,78 C-$ $0,8000 A B+4,34 A C-4,54 B C-1,62 A^{2}+$ $2,12 B^{2}-6,21 C^{2}$

\section{Donde:}

$Y_{1} \quad$ : Porcentaje de remoción de cadmio

$Y_{2} \quad$ : Porcentaje de remoción de plomo

A : : pH

$B \quad$ : Concentración de biomasa

C : Tiempo de contacto

Con la finalidad de asegurar un buen modelo matemático para el proceso de bioadsorción, se llevó acabo la prueba de significancia del modelo de regresión y se aplicó el análisis de varianza (ANOVA) para la remoción de cadmio y plomo con biomasa seca de $S$. marcescens M8a-2T. Los resultados del análisis ANOVA para la remoción de cadmio y plomo se muestran en la Tabla 3 . Los valores-p menores a 0,0500 indican que los modelos matemáticos son significativos para la remoción de cadmio y plomo (Parmar et al 2020). El alto nivel de significancia de los modelos indica la importancia de las variables $\mathrm{pH}$, concentración de biomasa y tiempo de contacto para la remoción de cadmio y plomo con biomasa seca de $S$. marcescens M8a-2T (Hasan et al 2009). No se han reportado otras cepas de $S$. marcescens con capacidad para remover metales pesados, sin embargo los resultados del presente estudio indican un mayor porcentaje de remoción de cadmio $(97,11 \%)$ y plomo $(98,63)$ que los obtenidos en otras investigaciones que usaron RSM para optimizar el proceso como Yuan et al (2019) quienes usaron Shewanella putrefaciens y 
lograron un porcentaje máximo de remoción de cadmio de $86,54 \%$ y Choińska et al (2018) que con cepas de Pseudomonas azotoformans lograron porcentajes máximos de remoción de $44,67 \%$ para cadmio y $78,23 \%$ para plomo.

\section{Optimización de las condiciones físico-químicas para la remoción}

En base a las ecuaciones cuadráticas de metodología de superficie de respuesta, se analizó el efecto de cada una de las variables independientes: $\mathrm{pH}$, concentración de biomasa y tiempo de contacto. El pH fue el parámetro más importante y tuvo un efecto positivo en la remoción tanto el cadmio como de plomo (Ecuaciones 1 y 2) con biomasa seca de $S$. marcescens M8a-2T. La concentración de biomasa seca de $S$. marcescens M8a-2T tiene un efecto negativo en la bioadsorción de cadmio y plomo (Ecuación 1 y 2), lo que significa que la remoción de dichos metales disminuye cuando la concentración de biomasa aumenta. El tiempo de contacto tuvo un efecto positivo en la remoción de cadmio (Ecuación 1) que aumentó a mayor tiempo de contacto y tuvo un efecto negativo en la remoción de plomo (Ecuación 2) que se redujo cuando se maximizó el tiempo de contacto.

Se observó que la biomasa seca de $S$. marcescens M8a$2 \mathrm{~T}$ logró remover hasta un $97,11 \%$ de cadmio a $\mathrm{pH} 4$, con $2 \mathrm{mg} / \mathrm{mL}$ de biomasa y 45 minutos de contacto, por otro lado, el porcentaje máximo de remoción de plomo fue de $98,63 \%$ a $\mathrm{pH} 4$, con $1 \mathrm{mg} / \mathrm{mL}$ de biomasa y 30 minutos de contacto.

El experimento número 4 produjo el mayor porcentaje de remoción tanto para cadmio $(96,33 \%)$ como para plomo $(98,63 \%)$ a pH 4, con $1 \mathrm{mg} / \mathrm{mL}$ de biomasa y 30 minutos de contacto como se presenta en la Tabla 4.

La variación de pH 2 a pH 4 del efluente minero produjo un aumento significativo en el porcentaje de remoción de cadmio y plomo debido al fenómeno de protonización, el cual ocurre cuando el medio tiene valores de $\mathrm{pH}$ menores a 7 , este fenómeno influye en la química de la solución y afecta la capacidad de adsorción de la biomasa (Tur-Naranjo et al. 2016).

Tabla 3. Análisis de la varianza (ANOVA) para la respuesta al diseño Box-Behnken.

\begin{tabular}{ccccccccc}
\hline & Fuente & $\begin{array}{c}\text { Suma de } \\
\text { Cuadrados }\end{array}$ & $\begin{array}{c}\text { Grado } \\
\text { de } \\
\text { libertad }\end{array}$ & $\begin{array}{c}\text { Media de } \\
\text { cuadrados }\end{array}$ & $\begin{array}{c}\text { Valor- } \\
\text { F }\end{array}$ & Valor-p & SD & significativo \\
\hline $\begin{array}{c}\text { Porcentaje de } \\
\text { remoción de } \\
\text { Cadmio }\end{array}$ & Modelo & 73,23 & 9 & 8,14 & 5,2 & 0,0204 & 1.25 & sadmo \\
\hline $\begin{array}{c}\text { Porcentaje de } \\
\text { remoción de Plomo }\end{array}$ & Modelo & 500,12 & 9 & 55,57 & 4,63 & 0,0279 & 3.46 & significativo \\
\hline
\end{tabular}

Tabla 4. Matriz del diseño experimental Box-Behnken: Respuesta experimental y teórica para la remoción de cadmio y plomo con biomasa seca de Serratia marcescens M8a-2T.*

\begin{tabular}{|c|c|c|c|c|c|c|c|c|c|c|c|c|c|}
\hline \multicolumn{3}{|c|}{ EXPERIMENTO } & 2 & 4 & 5 & 7 & 9 & 10 & 13 & 14 & 15 & 16 & 17 \\
\hline \multirow{4}{*}{$\begin{array}{c}\text { PORCENTAJE } \\
\text { DE } \\
\text { REMOCIÓN } \\
(\%)\end{array}$} & \multirow{2}{*}{ Cd } & Experimental & 95,32 & 96,33 & 92,31 & 93,62 & 94,49 & 93,18 & 93,99 & 93,77 & 91,63 & 97,11 & 93,43 \\
\hline & & Teórico & 96,56 & 97,25 & 91,39 & 93,55 & 93,55 & 93,55 & 94,02 & 94,06 & 91,60 & 96,16 & 93,55 \\
\hline & \multirow{2}{*}{$\mathbf{P b}$} & Experimental & 98,11 & 98,63 & 97,94 & 98,01 & 98,52 & 98,33 & 97,30 & 96,70 & 97,55 & 91,47 & 98,61 \\
\hline & & Teórico & 95,99 & 101,16 & 95,41 & 96,98 & 96,98 & 96,98 & 95,43 & 93,92 & 99,42 & 90,80 & 96,98 \\
\hline
\end{tabular}

*Todas las experiencias se hicieron por triplicado. 


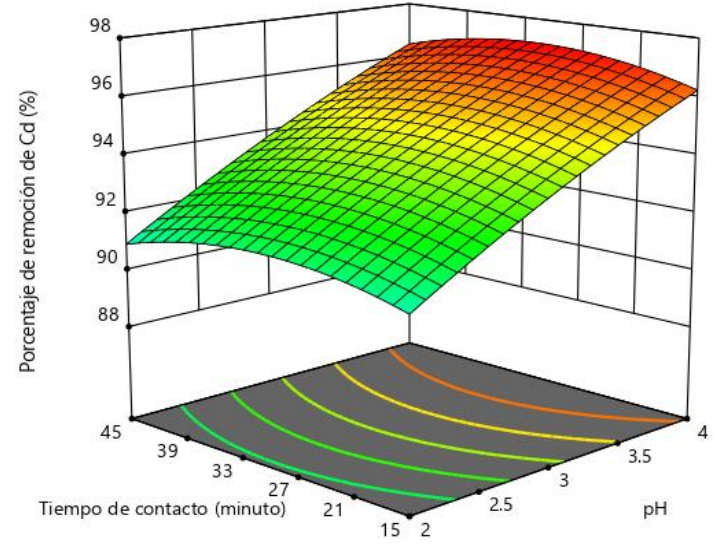

Figura 2. Gráfico tridimensional de superficie que muestra la influencia del tiempo de contacto y el $\mathrm{pH}$ en la bioadsorción de cadmio con biomasa seca de Serratia marcescens M8a-2T. Todas las experiencias se hicieron por triplicado.

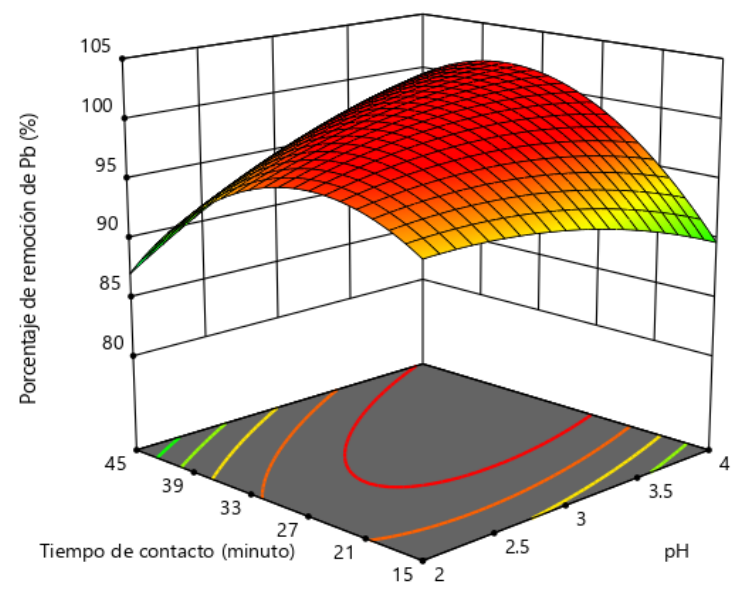

Figura 3. Gráfico tridimensional de superficie que muestra la influencia del tiempo de contacto y el $\mathrm{pH}$ en la bioadsorción de plomo con biomasa seca de Serratia marcescens M8a-2T. Todas las experiencias se hicieron por triplicado.

Según López et al. (2000) el aumento del pH, produce un aumento de las cargas negativas en la superficie de las células bacterianas hasta que todos los grupos funcionales relevantes están desprotonados, esto favorece la atracción electroquímica y la adsorción de los cationes, además existe una competencia entre los cationes con los iones $\mathrm{H}^{+}$para alcanzar los sitios de unión en las bacteria, por lo que a $\mathrm{pH} 4$, la protonización de los grupos funcionales aumentaría la concentración de cargas positivas y habría una interacción más fuerte entre los aniones y las células.

Kumar et al. (2009) observaron que el pH afecta la solubilidad de los metales y el estado de ionización de los grupos funcionales como los grupos amino, carboxilato y fosfato de la pared celular, estos grupos llevan cargas negativas que permiten la atracción de cationes a la pared celular, al aumentar el $\mathrm{pH}$, la superficie de la célula se carga más negativamente atrayendo cationes $\mathrm{Cd}^{2+}$ y $\mathrm{Pb}^{2+}$ favoreciendo la bioadsorción y al mismo tiempo se favorece la formación de las especies solubles $\mathrm{Cd}_{2} \mathrm{OH}^{3+}$ y $\mathrm{CdOH}^{+}$, mientras que el catión $\mathrm{Pb}^{2+}$ se encuentra estable en soluciones ácidas o neutras pero a medida que aumenta el $\mathrm{pH}$ se hidroliza parcialmente formando la especie $\mathrm{PbOH}^{+}$como lo señala Gutiérrez (2015). La formación de complejos de metales pesados es regulada por el $\mathrm{pH}$ y condiciona la especie química del catión en solución acuosa. Como se observa en las Figuras 2 y 3, el porcentaje de remoción de cadmio y plomo aumentó cuando se maximiza el $\mathrm{pH}$, la bioadsorción estaría siendo favorecida por la formación de complejos solubles del metal que también competirán con los sitios activos, la retención disminuiría, pero la disponibilidad de biomasa estaría compensando esta competencia entre cationes y complejos. Para Sheng et al. (2008) el aumento del pH por encima de 4 podría afectar negativamente el proceso de bioadsorción pues el pH influye en la fuerza de adhesión de los metales a la bacteria debido al cambio del estado de ionización de los grupos funcionales de la superficie bacteriana; mientras que la ionización del grupo carboxilato a $\mathrm{pH}$ 3 es débil y las fuerzas electrostáticas entre la superficie bacteriana y el metal son relativamente débiles; a pH mayores que 5, la presencia de $\mathrm{COO}^{-}$con carga negativa aumenta las fuerzas electrostáticas que involucran sitios de afinidad progresivamente más bajos para los iones metálicos (Al-Garni, 2005).

Los resultados de la presente investigación corroboran lo reportado por Gutiérrez (2015), quien observó que existe mayor capacidad de remoción de $S$. marcescens M8a-2T a medida que la concentración inicial de los metales aumenta, logró remover hasta $99,96 \%$ de cadmio y $93,93 \%$ de plomo a partir de 100, 200, y 400 ppm de dichos metales. En esta investigación, el mayor porcentaje de remoción de cadmio y plomo $(97,11 \%$ y 98,63\% respectivamente) se logró con la menor 
concentración de biomasa y la concentración de los metales presente en el efluente era mayor a $400 \mathrm{ppm}$. Rani et al. (2010) demostraron que el aumento de la concentración de biomasa puede reducir la bioadsorción debido a la reducción del crecimiento del microorganismo; mientras que Pons \& Fusté (1993) reportaron que la alta concentración de biosorbentes causa la aglomeración de células y como consecuencia se reduce la distancia intercelular, afectando la capacidad de adsorción de metales pesados. En el presente estudio, se removió hasta un $97,11 \%$ de cadmio con $2 \mathrm{mg} / \mathrm{mL}$ de biomasa; al respecto, Khan et al. (2016) observaron un incremento en la capacidad de bioadsorción de $\mathrm{Cd}^{2+}$ de Salmonella enterica 43C cuando se aumentó la concentración de biomasa de 5 $\mathrm{g} / \mathrm{L}$ a $30 \mathrm{~g} / \mathrm{L}$, concluyendo que una mayor concentración de biomasa proporciona una mayor área de superficie y mayores sitios de unión para el $\mathrm{Cd}^{2+}$, lo que aumenta la unión de $\mathrm{Cd}^{2+}$ con la biomasa y, por lo tanto, aumenta el porcentaje de remoción de dicho metal, sin embargo, el mayor porcentaje de remoción teórico de cadmio $(97,25 \%)$ es usando $1 \mathrm{mg} / \mathrm{mL}$ de biomasa seca de $S$. marcescens M8a-2T.

El porcentaje de remoción de plomo se redujo cuando se incrementó el tiempo de contacto. Se observó que el mayor porcentaje de remoción de cadmio fue a 45 minutos, mientras que el mayor porcentaje de remoción de plomo fue a los 30 minutos. Chowdhury \& Yanful (2013) atribuyeron esta diferencia en la velocidad de adsorción a la naturaleza química de la superficie del adsorbente: las distintas afinidades de los grupos funcionales y una mayor disponibilidad en la superficie de la biomasa puede acelerar la unión a los iones metálicos. García et al. (2016) atribuyen este hecho a que algunos iones metálicos se unen a la superficie celular, mientras que otros, de sorción más lenta, penetran al interior de las células; Gutiérrez (2015) observó que los sitios de unión de los metales se encuentran en la membrana externa de la pared celular de $S$. marcescens M8a-2T.

\section{CONCLUSIONES}

Se logró la remoción experimental de $97.11 \%$ de cadmio y $98.63 \%$ de plomo presente en el efluente minero de la Compañía Minera Alianza S. A. (Ancash, Perú), los parámetros óptimos para la remoción de dichos metales fueron: $2 \mathrm{mg} / \mathrm{mL}$ de biomasa, 45 minutos de enfrentamiento y $\mathrm{pH} 4$. Siendo el $\mathrm{pH}$ el parámetro de mayor importancia durante dicho proceso.

\section{Conflictos de intereses}

Los autores firmantes del presente trabajo de investigación declaran no tener ningún potencial conflicto de interés personal o económico con otras personas $\mathrm{u}$ organizaciones que puedan influir indebidamente con el presente manuscrito.

\section{Contribuciones de los autores}

Preparación y ejecución: AAQ, SGM; Desarrollo de la metodología: AAQ, SGM; Concepción y diseño: AAQ, SGM; Edición del artículo: AAQ; Supervisión del estudio: SGM.

\section{REFERENCIAS}

- Al-Garni, S. M. (2005). Biosorption of lead by Gramnegative capsulated and non-capsulated bacteria. Water $S a, 31$ (3), 345-350.

- Banerjee, A., Sarkar, P., \& Banerjee, S. (2016). Application of statistical design of experiments for optimization of As (V) biosorption by immobilized bacterial biomass. Ecological Engineering, 86, 1323.

- Bezerra, M. A., Santelli, R. E., Oliveira, E. P., Villar, L. S., \& Escaleira, L. A. (2008). Response surface methodology (RSM) as a tool for optimization in analytical chemistry. Talanta, 76(5), 965-977.

- Cañizares-Villanueva, R. O. (2000). Biosorción de metales pesados mediante el uso de biomasa microbiana. Revista Latinoamericana de Microbiologia-Mexico-, 42(3), 131-143.

- Castañé, P. M., Topalián, M. L., Cordero, R. R., \& Salibián, A. (2003). Influencia de la especiación de los metales pesados en medio acuático como determinante de su toxicidad. Revista de Toxicología, 20(1), 13-18.

- Castillo, L., Satalaya, C., Paredes, U., Encalada, M., Zamora, J. \& Cuadros, G. (2021). Pasivos ambientales mineros en el Perú: Resultados de la auditoría de desempeño sobre gobernanza para el manejo integral de los PAM. Documento de 
Política en Control Gubernamental (1ra ed.). Contraloría General de la República. Lima, Perú.

- Choińska-Pulit, A., Sobolczyk-Bednarek, J., \& Łaba, W. (2018). Optimization of copper, lead and cadmium biosorption onto newly isolated bacterium using a Box-Behnken design. Ecotoxicology and environmental safety, 149, 275283.

- Chowdhury, S. R., \& Yanful, E. K. (2013). Kinetics of cadmium (II) uptake by mixed maghemite-magnetite nanoparticles. Journal of environmental management, 129, 642-651.

- CIPER [Centro de Investigación Periodística]. 2011. Pasivos Ambientales Mineros en Perú: bombas de tiempo de las que nadie se hace responsable. Disponible en https://ciperchile.cl/2011/11/17/pasivos-

ambientales-mineros-en-peru-bombas-de-tiempode-las-que-nadie-se-hace-responsable/.

- Decreto Supremo $N^{\circ}$ 010-2010 [Ministerio del Medio Ambiente]. Por el cual se aprueban los Limites Máximos Permisibles - LMP, para la descarga de efluentes líquidos de Actividades Minero - Metalúrgicas. 21 de agosto de 2010.

- García, R., Campos, J., Cruz, J. A., Calderón, M. E., Raynal, M. E., \& Buitrón, G. (2016). Biosorption of $\mathrm{Cd}, \mathrm{Cr}, \mathrm{Mn}$, and $\mathrm{Pb}$ from aqueous solutions by Bacillus sp strains isolated from industrial waste activate sludge. TIP, 19(1), 5-14.

- Glave, M., \& Kuramoto, J. (2002). Minería, minerales y desarrollo sustentable en Perú. En V. L. Bacchetta (Ed.), Minería, minerales y desarrollo sustentable en América del Sur (1ra ed., pp. 529591). Centro de Investigación y Planificación del Medio Ambiente (CIPMA) \& Centro Internacional de Investigaciones para el Desarrollo (IDRC) Iniciativa de Investigación sobre Políticas Mineras (IIPM).

- Gutiérrez S.M. 2015. Estudio de la Bioadsorción de Cadmio y Plomo con Biomasa de Serratia marcescens M8a-2T, a Nivel de Laboratorio. Tesis doctoral, Universidad Nacional Mayor De San Marcos, Lima. Perú. 29 p.

- Hasan, S. H., Srivastava, P., \& Talat, M. (2009). Biosorption of $\mathrm{Pb}$ (II) from water using biomass of Aeromonas hydrophila: central composite design for optimization of process variables. Journal of Hazardous Materials, 168(2-3), 1155-1162.
- Khan, Z., Rehman, A., Hussain, S. Z., Nisar, M. A., Zulfiqar, S., \& Shakoori, A. R. (2016). Cadmium resistance and uptake by bacterium, Salmonella enterica 43C, isolated from industrial effluent. AMB Express, 6(1), 54.

- Kumar, R., Singh, R., Kumar, N., Bishnoi, K., \& Bishnoi, N. R. (2009). Response surface methodology approach for optimization of biosorption process for removal of $\mathrm{Cr}$ (VI), Ni (II) and $\mathrm{Zn}$ (II) ions by immobilized bacterial biomass sp. Bacillus brevis. Chemical Engineering Journal, 146(3), 401-407.

- Lopez, A., Lazaro, N., Priego, J. M., \& Marques, A. M. (2000). Effect of pH on the biosorption of nickel and other heavy metals by Pseudomonas fluorescens 4F39. Journal of Industrial Microbiology and biotechnology, 24(2), 146-151.

- Parmar, P., Shukla, A., Goswami, D., Patel, B., \& Saraf, M. (2020). Optimization of cadmium and lead biosorption onto marine Vibrio alginolyticus PBR1 employing a Box-Behnken design. Chemical Engineering Journal Advances, 4, 100043.

- Pons, M. P., \& Fuste, M. C. (1993). Uranium uptake by immobilized cells of Pseudomonas strain EPS 5028. Applied Microbiology and Biotechnology, 39(4-5), 661-665.

- Rani, M. J., Hemambika, B., Hemapriya, J., \& Kannan, V. R. (2010). Comparative assessment of heavy metal removal by immobilized and dead bacterial cells: a biosorption approach. African Journal of Environmental Science and Technology, 4(2).

- Rubio, D. I., Calderón, R. A., Gualtero, A. P., Acosta, D. R., \& Rojas, I. J. (2015). Tratamientos para la remoción de metales pesados comúnmente presentes en aguas residuales industriales. Una revisión. Ingeniería y Región, 13, 73-90.

- Sandoval, G. M. (2006). Aproximación teórica a la biosorción de metales pesados por medio de microorganismos. Revista CES Medicina Veterinaria y Zootecnia, 1(1), 77-99.

- Sheng, X., Ting, Y. P., \& Pehkonen, S. O. (2008). The influence of ionic strength, nutrients and $\mathrm{pH}$ on bacterial adhesion to metals. Journal of Colloid and Interface Science, 321(2), 256-264.

- Tur-Naranjo, E., de los Milagros Orberá-Ratón, T., Romagosa-Álvarez, Y., \& Pérez-Silva, R. M. 
(2013). Bioadsorción de plomo (II) por biomasa microbiana seca: Efecto del pH. Revista Cubana de Química, 25(1), 75-81.

- Vilela-Pincay, W., Espinosa-Encarnación, M., \& Bravo-González, A. (2020). La contaminación ambiental ocasionada por la minería en la provincia de El Oro. Estudios de la Gestión: revista internacional de administración, (8), 210-228.

- Witek-Krowiak, A., Chojnacka, K., Podstawczyk, D., Dawiec, A., \& Pokomeda, K. (2014).
Application of response surface methodology and artificial neural network methods in modelling and optimization of biosorption process. Bioresource technology, 160, 150-160.

- Yuan, W., Cheng, J., Huang, H., Xiong, S., Gao, J., Zhang, J., \& Feng, S. (2019). Optimization of cadmium biosorption by Shewanella putrefaciens using a Box-Behnken design. Ecotoxicology and environmental safety, 175, 138-147. 